
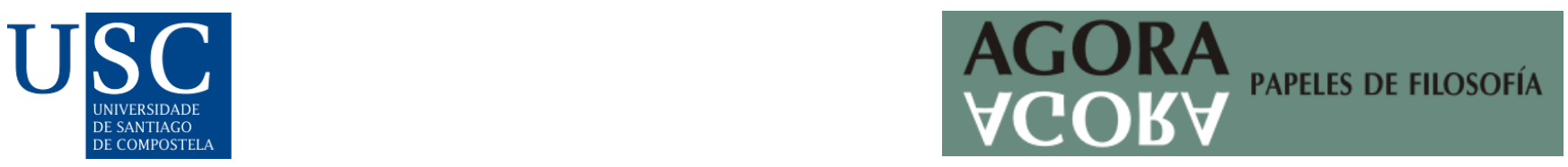

Agora. Papeles de Filosofía, 41(1), 2022. ISSN: 2174-3347

https://doi.org/10.15304/agora.41.1.7434

Estudios

\title{
DAR LA MANO: LA POLÍTICA COMO AMISTAD
}

\author{
Víctor Samuel Rivera ${ }^{1}$ iD \\ ${ }^{1}$ Universidad Nacional Federico Villarreal, Perú
}

Recibido: 24/01/2021; Aceptado: 09/03/2021

\section{Resumen}

El presente texto intenta dar unos alcances iniciales para un enfoque constructivista de la filosofía política y la organización social basado en el hecho de la amistad; particularmente en el saludo tomado como un acontecimiento de amistad. El mero saludo, el acercamiento más básico de empatía, sería el acontecer de un mundo, de un mundo entero caracterizado por su exigencia de ser, de ser realizado y conservado. Esta exigencia procedería de un fondo arcaico insondable, que sería accesible en la idea del número de los amigos. Se trata de una aporía que muestra a la vez el carácter abierto, pero no infinito, de un grupo de referencia basado en la ternura de algo común.

Palabras clave: amistad; comunidad política; número; Jacques Derrida; San Agustín

\begin{abstract}
This text tries to give some initial scopes for a constructivist approach to political philosophy and social organization based on the fact of friendship; particularly in the greeting taken as an event of friendship. The mere greeting, the most basic approach to empathy, would be the happening of a world, of a whole world characterized by its demand to be, to be realized and preserved. This requirement would come from an unfathomable archaic background, which would be accessible in the idea of the number of friends. It is an aporia that shows both the open, but not infinite, character of a reference group based on the tenderness of something common.
\end{abstract}

Keywords: friendship; political community; number; Jacques Derrida; St. Augustine

\section{INTRODUCCIÓN}

El presente trabajo es el intento de una fenomenología de la amistad con el propósito de extraer de ella sus presupuestos políticos. Vamos a partir de la experiencia del encuentro y el saludo, del mero dar la mano. Una y otra persona se encuentran; reconocen quizá sin palabras algo que los vincula, unos sentimientos de comunidad que hacen a cada uno relevante para el otro. En tiempo reciente Giorgio Agamben ha recordado en El amigo, un texto breve sobre ética y política, que Aristóteles tuvo la sugerencia de relacionar los encuentros humanos y, más particularmente, las 
relaciones de amistad, con el horizonte más general de llevar una vida política. Agamben subraya la anotación de Aristóteles de que la amistad, como una relación de dos, equivale a algo semejante a una comunidad que se halla basada en el afecto recíproco ${ }^{1}$. En efecto, en el libro IX de la Ética a Nicómaco, Aristóteles hace la sugerencia de que la amistad es un género de comunidad, y que esta comunidad es análoga a la comunidad ciudadana o política. Las reflexiones de Agamben retrotraen de modo polémico (sin mencionar el libro) a Políticas de la amistad, un texto en que Jacques Derrida desarrolla una serie de apuntes sobre la obra de Aristóteles que venimos de citar. En Políticas de la amistad el autor francés plantea una estrategia deconstructiva del aspecto político de la amistad; se desarrolla con este objetivo una serie de razonamientos aporéticos respecto de la amistad y los sentimientos de comunidad que en ella se ponen de manifiesto, así como el vínculo problemático entre una comunidad de amigos y una comunidad política, sobre quiénes, cuántos y bajo qué criterios "nosotros" somos amigos".

Aunque en El amigo Agamben intenta rescatar el contexto original aristotélico y un cierto énfasis en los sentimientos empáticos que unen a los amigos, consideramos que la interpretación aporética que hizo antes Derrida se halla vigente a través de los sólidos trabajos en la misma línea que publicara posteriormente Laura Llevadot ${ }^{3}$.

En oposición a las derivaciones de Derrida sobre la interpretación de Aristóteles sobre la política ${ }^{4}$, y quizá con ánimo de dar cuerpo a las escuetas referencias de Agamben, el núcleo de nuestra argumentación apunta a incidir en la idea de que la amistad expresa de alguna manera un vínculo político. Insistiremos en que la amistad señala un vínculo desde siempre basado en la aproximación empática que une a ciertos seres humanos; para desarrollar esto vamos a salir de la práctica de la amistad como una virtud, que es el enlace desde la Ética a Nicómaco a Agamben, a una práctica que antecede y anuncia en general la amistad, que es el gesto del saludo, darle a alguien la mano. Saludar a otro, en nuestro concepto, implica una totalidad humana, una comunidad que bien podrá ser llamada también ciudad o comunidad política. Desde nuestra perspectiva, saludar sería antes que una mera acción particular, un acontecimiento político: reconocer a un humano (o un grupo de ellos) como vinculado en compromisos que abarcan un número indefinido de otros bienvenidos en el sentimiento de empatía.

Tomando el dar la mano a alguien como punto de partida, intentaremos mostrar que se trata de un acto de preferencia empática, del que recibe en cada caso el saludo sobre otros que no lo reciben (o no lo acogen); esto tiene la finalidad de mostrar cómo el saludo a otro, de manera enteramente anticipada, trae consigo presupuestos amplios y complejos de vinculatividad o comunidad. En la experiencia ordinaria estos presupuestos son experimentados de manera difusa, no precisable, pero son percibidos como una totalidad de sentido; esto último hace referencia a un sentimiento que hemos denominado "ternura de la amistad". Este sentimiento será tratado de manera ontológica, para lo cual la argumentación se valdrá del rol de los sentimientos en la comprensión humana, tanto desde El Ser y el Tiempo de Martin Heidegger como desde el principal antecedente de esta obra, las reflexiones de René Descartes en torno de las pasiones o sentimientos. Luego pasaremos a desarrollar la idea de que la comprensión del saludo contiene presupuestos de vinculatividad y comunidad, que son los mismos que Derrida transformó en un discurso aporético y aquí trataremos de afrontar con un enfoque fenomenológico de la experiencia de contar a alguien como amigo (cuando lo saludo, por ejemplo). Esto nos conduce a un concepto de comunidad/ciudad que intentaremos desarrollar desde los presupuestos del saludo usando como pauta argumentativa la obra de San Agustín De civitate Dei (La ciudad de Dios). 
Vamos a concluir este texto vinculando la idea de que el que saluda pertenece a una comunidad política, a la que se reconoce en el saludo, para sugerir que el dar la mano no solo expresa alguna identidad o pertenencia difusa, sino una serie vasta de compromisos implícitos que, en el saludo, son honrados y reconocidos como un acontecimiento de la naturaleza política y comunitaria en la que se alcanza el sentido de la existencia.

\section{DARLE LA MANO A ALGUIEN}

Una persona deambula arbitrariamente. De pronto, sin haberlo pensado antes y sin que fuera predecible en ningún sentido, aparece alguien conocido, o que se cree conocer. Y entonces hay un impulso, en principio irrenunciable, por saludar. Dar la mano, estrecharla a alguien que la ofrece u ofrecérsela al otro, es uno de los fenómenos de acercamiento humano, quizá por su carácter cotidiano y ordinario, a los que menos se ha prestado atención filosóficamente. Alguien se acerca y le sonreímos, o le hacemos un gesto de reconocimiento de lejos, como sacudir suavemente una mano y agitarla o alzar las cejas, o dar una mirada dulce. Vamos a hacer a partir de la reflexión del saludo y aquello que regularmente expresa una propuesta de pensar la política; el objeto es pensar el ámbito político desde la amistad, y quizá desde antes de la amistad efectiva, desde una mera empatía dirigida a otro que luego es realizada en el saludo, y se transforma en un acto de amistad. La empatía que el saludo realiza incluye un reconocimiento de la persona que en cada caso es saludada, como una persona distinta del resto, ante el que se sigue de largo; dar la mano pareciera un reconocimiento sin importancia; presupone, sin embargo, una cierta complejidad de compromisos previos sobre la base de los cuales el saludo tiene, respectivamente, sentido. Pero siendo esto último, la complejidad de los compromisos humanos, un lugar común algo bastante antiguo en el pensamiento sobre las sociedades humanas, sea permitido dar una mirada al pensamiento que no se tiene en el simple acto de dar la mano.

Debe subrayarse que dar la mano es un acto de amistad, incluso cuando es ofrecido a un desconocido. Uno no siempre es antes amigo de quien saluda. En este sentido, dar la mano es un acto abierto $\mathrm{y}$, puesto que nadie se halla de hecho a priori excluido de poder ser saludado, es un acto sin fronteras definibles. Hay muchas formas de saludar, asunto regido según la cultura; lo que no varía en cambio es que se trata de una expresión de algo tan arcaico o primitivo que no pensamos sobre eso sino cuando queremos retirarlo (quitar el saludo) en lugar de darlo. En este sentido, el saludo es un a priori de la conducta humana relativo al trato con otro. Muestra amistad. Por ello saludar hace amigo al otro, establece una cercanía que en la vida ordinaria se expresa diciendo que se da o se dio la mano al otro "como amigo". Como no hay antecedentes sobre saludar y dar la mano, nos remitiremos al texto anunciado al inicio, el texto más significativo que la tradición filosófica ha consagrado a la amistad, el capítulo IX de la Ética a Nicómaco de Aristóteles ${ }^{5}$. Como observamos en la introducción, hizo allí notar el de Estagira que las relaciones de amistad presuponen una cierta dimensión política, en la que justamente es como si el otro que es amigo fuera como un ciudadano ${ }^{6}$. Sostiene allí la idea de que el amigo (en tanto es otro) es como un otro yo, uno de quien en cada caso podría decirse se es amigo en calidad de que es como uno mismo ${ }^{7}$. Esto ocurriría porque cada uno de los referentes de la amistad se hallaría comunicado en una unidad anterior, que los sobrepasaría a ambos a la par que le da sentido a su encuentro. Con esto presente, volvamos ahora al mero dar la mano. 
Algo que no fue tematizado por Aristóteles es que acercarse a alguien para saludarlo es ya un modo de hacerlo amigo. Así como un amigo es como un ciudadano, el otro a quien saludo es como un amigo. Esto ocurre incluso de manera pensada o imaginaria, como cuando se sonríe ante el libro de un autor que uno lee, o se saluda frente al retrato de un monarca o un artista, o se pone una vela a un santo. Y así como ser amigo de alguien no es solo amar su persona, al darle la mano a alguien hay algo adicional que sobrepasa al ser humano que en cada caso se ha saludado, lo cual vale de modo peculiar en el saludo imaginario o simbólico, pero con mayor motivo en el saludo ocasional al desconocido, tratado entonces como amigo. En el acercarse a saludar, la amistad aparece como una suerte de exigencia a la que el saludo contesta ${ }^{8}$; aunque se trate de un saludo precario y al paso, hay algo como anterior que recae en el que es saludado para tratarlo "como amigo" en ese momento. Lo anterior puede vincularse con las reflexiones de Aristóteles sobre la amistad en un aspecto fascinante del saludo, que es el reconocimiento del otro; impulsado uno a saludar, se le exige a uno realizar una semejanza de uno mismo como el otro, hasta en el desconocido, pues uno saluda a su semejante; se trata de algo que el saludo mismo pide, incluso cuando éste es dado a un superior (o inferior) en jerarquía. En realidad, ya que saludamos ocasionalmente y a desconocidos, en el acto de saludar tiene prioridad no tanto el ser humano mismo X o Z, cuanto la circunstancia de saber o descubrir a ese otro X o Z como un (otro) yo de quien uno se encuentra como amigo. Se trata del otro Tal al modo de un acontecimiento. Reconocer es acontecer.

Reconocer como amigo a la persona X o Z cuando uno lo saluda es lo que podemos llamar un acontecimiento de la amistad. Si se lee con atención a Aristóteles, en el encuentro con el amigo hay una especie de ternura, una disposición de ánimo de satisfacción, que acompaña a la experiencia de ver acontecer en cada caso a un otro yo mismo9; esta disposición de ánimo es el aspecto que indica y sostiene la amistad como un acontecimiento, vale decir, como un cierto modo de relación que es reconocida en el estado de ánimo que la aloja. Un acontecimiento o un evento es como cualquier cosa que pasa, como pasar de un día calendario al siguiente ${ }^{10}$; en este caso, sin embargo, el acontecimiento de la amistad se hace manifiesto en la experiencia de una intensidad emocional relacionada en el hecho de la selección del que se saluda y se le da reconocimiento. Se lo ha preferido a otro, es un otro que es preferible; frente a los omitidos del acto del saludo, no reconocidos como amigos, por así decirlo ${ }^{11}$. Ser preferible en un amigo, lo cual acompaña la ternura que por él se siente, es en contraste con otro a quien aún no se ha saludado o no se saludará. Quizá se pueda explicar qué motivos hacen preferible al que se saluda; es un hecho curioso que esos motivos sean sin embargo siempre sobrepasados por lo que hace saludar, ciertamente un principio anterior y más exigente.

Pónganse el lector en la posición del amigo que saluda. El lector amigo que lee esto está en situación análoga al que saluda; se halla en realidad empujado a leer (como uno se halla empujado a saludar) por un motivo que ya no es una razón: algo más antiguo, más originario y arcaico que se impone. Sea permitido escribir que eso arcaico a lo que antes nos referimos es un acontecimiento, es decir, no es la persona saludada, sino el impulso por saludarla y tratarla como amigo; las razones aparecen allí como subsidiarias, a la manera de abrazos y miradas de complicidad ante algo más maravilloso que bien sabemos aconteció al saludar. Debe agregarse aquí que la ternura que es despertada de este modo es un tipo de sentimiento que aparece enlazado en el otro como a una persona, pero que honra algo que se halla en esa persona, pero la excede, por lo mismo que podría remitirlo a otra. En este sentido, la ternura que acontece abarca una especie de mundo. Vamos a tratar esto con más detalle. 
Con el permiso del docto, diremos que hay algo objetivo, imperioso en saludar, que se presenta a la vista como un mundo de cosas comunes con el otro ${ }^{12}$. Cuando yo saludo acontece la ternura por otro, por otro en que yo mismo soy. Lejos de tratarse de un mero sentimiento, se trata del acontecer de una realidad que tiene lugar en el saludo mismo. Sea permitida aquí una anotación. Como bien sabe el docto, fue Martin Heidegger quien definió de manera perdurable el rol de los sentimientos en la comprensión humana en general en Sein und Zeit (1927) ${ }^{13}$. Démosle unos apuntes complementarios a ese libro ahora para reforzar la idea de que saludar a alguien, incluso a uno que no se conoce, trae consigo el acontecer de una realidad arcaica, anterior y más grande que es reconocida en el encuentro del saludo.

Heidegger hizo de los sentimientos una condición necesaria de la comprensión, de tal modo que los sentimientos (como la ternura del saludo) son una suerte de a priori de la comprensión de cualquier cosa cuando es un ser humano quien la tiene. En esto Heidegger siguió un modelo de comprensión que puede reconocerse en Aristóteles, que lo había así ya tematizado en el Libro II de su Retórica ${ }^{14}$ Cuando se tiene un sentimiento, este implica a su vez un tipo de comprensión de algo, indica y envía hacia algo que acontece en el ser sentido como una experiencia; esta remite a su vez a una cierta constelación de cosas que son comprendidas y en cuyo ámbito hace sentido reconocer ese algo como algo. Aquello a lo que se es enviado y acontece en el sentimiento es una dimensión de la realidad que en nada es arbitraria, lo cual se muestra porque exige y pide y compromete; lo hace justamente en nuestro caso al uno ser empujado al saludo ${ }^{15}$.

La lectura de Heidegger, en especial en lo relativo a la comprensión relacionada a los sentimientos, parece remitir de modo inequívoco a su notable antecedente: Las pasiones del alma de René Descartes. Descartes señaló también la particularidad de los sentimientos como una dimensión del comprender: los sentimientos son llamados "pasiones" para significar experiencias que sentimos como consecuencia o vínculo con algo que nos ha impresionado e impresiona, para lo cual se requiere también que nos exceda; lo que impresiona emocionalmente nos hace padecer (que es lo contario de actuar), y esto porque se trata de una experiencia que remite a una esfera anterior que se caracteriza por ser indisponible para el que es afectado por ella ${ }^{16}$. Este ámbito indisponible es el que actúa y cuya acción reconocemos en el sentimiento; la empatía que empuja a saludar aparece como acontecimiento de un ámbito anterior que compromete a la vez que significa la ternura del encuentro.

De la reflexión sobre el carácter anterior e indisponible de los sentimientos relativos a la comunidad surge la consideración siguiente: el saludo empático a otro, en tanto es un acontecimiento, se reconoce como una cierta ternura, un sentimiento inequívoco de cercanía y aun amor; este sentimiento revela y manda algo exigido y que uno, al amar, anhela como en alguna medida admirable y necesario. Con la referencia a la descripción de la amistad como virtud en el libro IX de la Ética a Nicómaco, en el acto de saludar como amigo se hace manifiesto un ámbito indisponible; uno es empujado desde ese ámbito a cumplir como amigo. En el ser empujado a ofrecer la mano hay algo que, justamente, por ser indisponible, no es ni de uno ni de otro en particular, pero ni siquiera de ambos como amigos (que en el caso del desconocido no son) ni de otros más amigos que fueran amigos de éstos y se integraran del saludo.

Sea perdonada la insistencia en que las pasiones, como ser empujado a saludar, no son meros sentimientos. Hans-Georg Gadamer ha llamado "solidaridad" a lo que reconocemos el ámbito indisponible que empuja en el dar la mano al otro ${ }^{17}$. Es el sentimiento que plasma una afinidad con otro. Aunque la ternura del saludo tiene la apariencia de un sentimiento relacionado con el carácter 
familiar, la familiaridad de un reconocimiento ("te reconozco porque te conozco desde antes"), es manifiesto que cuando la ternura de la amistad acontece, puede ser completamente súbita sin que haya algo previo en el encuentro en el trato con Tal y Tal. Es lo que sucede con saludar de pronto por simpatía a un completo extraño, en la estación del metro, por ejemplo. Si seguimos el esquema de Aristóteles y Descartes, que adoptaría luego Heidegger, sabemos ya que esta ternura es "pasión" porque responde a algo actuado en nosotros; no solo es algo que sentimos, sino también la acción operada de algo en nosotros, que por el mismo motivo nos apasiona y estimula, de tal modo que reconocemos en la pasión así generada un motivo de atención e interés por algo. La solidaridad, el ámbito que empuja al saludo es una exigencia relacionada con cosas que hacer.

La operación actuada en la pasión es antes que un estado, la presencia manifiesta de algo anterior, pero algo que no solo existe y acontece en la pasión, sino que pide cosas y hace demandas de cosas que hacer en la realidad, por ejemplo, darle la mano al extraño y con los motivos postergados.

Hagamos una precisión historiográfica. Esta manera de enfocar las pasiones que hemos remitido a Heidegger es importante por el contexto en que fue pensada, es decir, porque se hizo en la primera mitad del siglo XX. Es importante recordar el ambiente de la década de 1920-1930, colonizado culturalmente por el cientificismo ${ }^{18}$. Como esto del cientificismo es una creencia social antes que una filosofía, y no ha dejado de ser vigente aun en algunos lugares (como los Estados Unidos) debe decirse que es un dispositivo según el cual una teoría o un razonamiento práctico se hace legítimo como medio de convencimiento si y solo si adquiere las características de un conocimiento científico ${ }^{19}$; debe por tanto tener "universalidad" (aplicarse en diversidad de circunstancias sin variaciones), lo cual califica argumentos o teorías de “objetivos". El afán de objetividad viene paralelo y frente a lo que sería "subjetivo" y, por la misma razón, carente de validez o de obligatoriedad (o incluso de sentido). Decir de un argumento, una idea o una teoría, etc. que son legítimos en un ambiente cientificista implica entonces la descalificación argumentativa de cosas como los sentimientos, que característicamente no son ni objetivos ni universales. No fue poca cosa darles un lugar importante en 1927 como Heidegger hizo y no lo es ahora tampoco si, como es posible creer suceda, algún lector se le pasa por la mente que argumentar a partir de lo que se siente es relativista o subjetivo, etc.

Aunque hay indicadores que sugieren en Heidegger la lectura de Descartes y su tratado sobre las pasiones, la idea de que los sentimientos humanos pueden funcionar como mensajes relativos a acciones es sin embargo un tópico argumentativo que hace la filosofía antes de Heidegger o Descartes. Lo hizo Platón en El Banquete, por ejemplo; Platón argumenta allí que el sentimiento de atracción erótica (en este caso, el que un joven bello y un adulto pueden experimentar, aunque para no hacerse problemas puede uno igual pensar la situación entre un muchacho común y su novia) es algo así como la prueba de una esencia, de un bien anterior que se expresa en las exigencias deseadas y aun realizadas del amor. Lo mismo ocurre en el Eutifrón, donde a partir del testimonio de la piedad, que es un sentimiento respecto de las cosas superiores o santas, se argumenta que, en efecto, hay algo superior o santo que exige ser cumplido en acciones relativas a los dioses. Los sentimientos son principios argumentativos, y dan fe de realidades de diversa índole experimentadas en ellos. Desviemos la vista hacia algo menos erótico, aunque también ciertamente menos sagrado.

Pensemos ahora en un numismático. Este se encuentra en una tienda de viejo, entre abarrotes y diversas chucherías, con una moneda interesante; es interesante porque puede en cada caso 
clasificarla o avaluarla. Ahora hagamos lo mismo con el apasionado de la arquitectura, que descubre, aprecia o ensaya proyectos, etc. En todos los casos, en el mero acercamiento, el saludo a lo amado corresponde con llevar a cabo formas de comportamiento vinculante, que toma por compromisos con el que en cada caso es como amigo, como el desconocido al que le doy la mano; lo mismo hace el arquitecto apasionado con diseños o el numismático sorprendido con una moneda que recoge del piso con la mano. En todos los casos hay una realidad acontecida que exige acciones dulcemente, por así decirlo, pues las solicita en una cierta ternura de descubrir que tal y tal; en el último se trata de la exigencia de la ternura con aquel que se saluda como amigo: esto es prueba por sí mismo de la realidad de algo que empuja al saludo. El arquitecto que restaura la antigua capilla de la dinastía austriaca debe comprender bien cómo allí acontece un saludo: se hacen presentes otros como amigos siendo ausentes y por qué, por lo mismo, la comunidad de lo que a él se le exige, restaurar la obra legada de la que él mismo es parte y legatario, abarca una amistad emergida de una antigüedad insondable, que lo abarca a él mismo siendo, como es, agnóstico.

El mundo entero que va en el saludo recae como un acontecimiento, por así decirlo, en el que es reconocido en el saludo mismo, como este saludo dado a Tal, ofrecido en compromiso a Tal. Veamos ahora un tema que acompaña al saludar como amigo: que genera (o presupone) vínculos, de los que las acciones exigidas son muestra.

\section{LA AMISTAD COMO CIUDAD}

La amistad, y aún más el sentimiento de afinidad del que parte, pensaba Aristóteles, viene con un tipo de comunidad, una especie de mundo de cosas que hacer que se hallan a la expectativa de ser hechas; la ternura expresada por el saludo ofrecido funda y manifiesta una realidad que acontece cuando uno se encuentra con el otro como un amigo; aunque el saludo es repentino, la amistad se reconoce desde siempre. Es interesante que esto suceda aun en la hipótesis de que se ignora, o no se conoce bien, o no se pudiera explicar en absoluto jamás claramente las razones del saludo. De hecho, la definición de qué es un amigo en el Libro IX de la Ética a Nicómaco aparece en la misma secuencia en que se define al hombre como un ser que es político, es decir, como un ser cuya realidad solo tiene sentido en la ciudad o polis. Hay que entender la ciudad como algo político en el sentido de allí donde es posible que los amigos se encuentren, donde la amistad es así "natural" ${ }^{20}$. No se trata de vivir lo político tras una muralla, pues la definición política del amigo vale para el cazador, el hombre campestre, el rural o el itinerante que se encuentra con un amigo camino de la montaña. Añadamos nosotros: vale para el que se encuentra en el campo con otro cualquiera (un desconocido) a quien se siente empujado de súbito a ver como amigo. Sin duda alguna la amistad fuera de la ciudad solo es hecha lugar en un saludo si hay o hubo o es posible que haya algo como una ciudad de referencia que sea el espacio para el saludo. Un saludo en el campo es un saludo político.

Cuando acontece el saludo, éste responde a la dimensión anterior al amigo que deseamos tener en el desconocido y que, curiosamente, permite que la amistad con él acontezca (de la nada); cuando el saludo acontece, ocurre lo mismo desde el otro. En términos generales, presupone lo que Aristóteles resumió en "ciudad": una comunidad de intereses amplios, así como un reconocimiento de estos intereses al modo de compromisos exigibles en un todo "natural" que los hombres deben, sin embargo, hacer. Es notorio que la definición de la comunidad política que da Aristóteles es así el lugar natural de la amistad ${ }^{21}$. El mero hecho de dar la mano es un reconocer en el otro el ámbito de intereses compartidos; ciertamente no un ámbito definido y de marcas claras, "dentro del muro de 
la ciudad", por así decirlo, sino un ámbito fluido, indefinido, variable, que es fácil reconocer que varía dependiendo de a quién se le da la mano e incluso con qué énfasis. No hay tal cosa como el muro del saludo, aunque haya ciudades con muros. Nunca sabemos el límite de lo siempre compartido, pues dar la mano implica el conocimiento de que no podemos abarcar lo que en cada caso compartimos. Este conocimiento es aporético, pues implica que no hay una descripción de lo que se supone se reconoce. Saludar al vecino, al compañero de hobby, al correligionario político o al que encontramos cada domingo en el culto no genera nada como un muro y solo dice referencialmente de su contexto.

Lo que en la amistad es así indicado tiene lugar como un mundo y de su ser habría que declarar que acontece en el mismo acto de dar la mano, o alzarla, o desplazarla de un lado a otro, o estrechar los cachetes, según exija en cada caso el mundo que acontece en el encuentro de una cierta amistad. Aristóteles pensó que la amistad, eso que acontece, es como una ciudad; un lugar donde se vive y vive el amigo con quien en cada caso despierta la ternura del saludo y que bien vale así descrita para el que le doy la mano sin conocerlo porque me siento empujado a hacerlo. La comunidad que es así como una ciudad implicaría (se permita ser redundante) algo político, ya que manifiestamente no solo es algo personal, de uno mismo o del en cada caso reconocido en la ternura de darle la mano. Detengámonos ahora en eso un poco y volvamos a las sugerencias de Aristóteles en la Ética a Nicómaco.

Los amigos, al reconocerse el uno como el otro en cada caso, constituyen con sus actos empáticos un lugar donde están uno y el otro, una comunidad ${ }^{22}$, vale decir, un lugar de cosas comunes, algo semejante a grandes rasgos a lo que hemos denominado mundo de cosas que hacer. El que en cada caso se reconoce como amigo de su amigo encuentra que ambos son de alguna manera miembros ciudadanos de un cierto mundo determinado que los llama en la ternura de su encuentro ${ }^{23 .}$ Cuando se es empujado al saludo, es un mundo el que llama. Entendemos por mundo el horizonte más vasto en que tiene o es incluso posible que tenga lugar (aunque en la práctica no lo tenga) la ternura de los amigos como algo con sentido; definimos como mundo aquello anterior en que la amistad acontece y se sitúa a sí misma como una ternura, el lugar que une y asocia y hace posible que la amistad sea real (en oposición una cierta empatía conceptual, teórica, construida, imaginada o elegida). Es en este mundo que la amistad se hace real y posible al mismo tiempo en el trato con otro, que es como una especie de trato con uno mismo; los amigos así unidos eran para Aristóteles ciudadanos de un pequeño Estado de dos. Pero la ciudad donde el que saluda como amigo encuentra acontecida es el principio de una ciudad donde dos es un número ocasional.

Se pide al lector recordar que las amistades parecen ser de dos porque se cuentan numéricamente desde dos. La relación más básica del saludo y la amistad es entre uno y otro que son amigos (y de este modo se reconocen al saludarse), pero que hay amistades de tres, de cuatro y así, sin que eso altere la naturaleza de lo que es anterior, de si es lo mismo lo que los une a todos sin importar su número. Uno da la mano al amigo, o a un desconocido como amigo en lo mismo; puede saludar también a una multitud, como lo hacen las estrellas de cine en las galas o los monarcas en las ceremonias públicas institucionales. Esto que es lo mismo lo es no tanto por las personas como por la ternura, y ésta por el mundo de cosas que hacer que acontece en el sentimiento que empuja a saludar (al amigo o incluso al extraño saludado, que es como amigo). Saludar, tratar como amigo, hace un mundo de innumerables personas y es central para este texto no ver la amistad como algo semejante a la ciudad, sino entender que la ciudad (el mundo político) puede ser definido como el número de los que se cuenta como amigos a quienes se saludaría. Para desarrollar esto debemos abordar una reflexión sobre Jacques Derrida. 


\section{DERRIDA: EL NÚMERO DE LA CIUDAD}

Jacques Derrida recordó en un seminario de 1985 la dificultad del paso de los amigos que hacen un número (tal o tal) a la idea más amplia de un mundo donde los amigos configuran un horizonte político; el tema fue desarrollado en un texto de 1994 que se denomina Políticas de la amistad, donde Derrida comenta el capítulo IX de la Ética a Nicómaco ${ }^{24}$. Recordemos ahora lo que Derrida quiso comentar. Una vez destacado que ser amigos de modo natural es algo posible referido a un ámbito previo más complejo y ontológicamente anterior, Aristóteles desestima la idea de que por ser algo que acontece en una ciudad, sea la ciudad misma un conjunto de amigos; asocia a esto varias ideas, como el tema de si lo que llamamos aquí ternura se puede dar a muchos (para nuestro caso, en lugar de solo al que acontece que es saludado), y luego propone esta cuestión: cómo y con qué criterio contar a los amigos, saber a cuántos debía considerarse o no como amigos $^{25}$. En este caso es nuestro objeto también el "como amigo" aplicado a quien nos da o a quien damos ternura como amigo.

Es obvio que subyace algún tipo de aporía en la situación de contar quién es o no amigo, pues presupone también la exclusión del que no es amigo o no debe ser considerado para el conteo, siendo siempre problemático saber qué hace o no contable a Tal o Tal en la lista. El que esto firma no recuerda que Derrida haya podido dar cuenta satisfactoriamente de este asunto; cómo se determina el número, desde qué número los amigos hacen una comunidad o una ciudad ${ }^{26}$; se trata del paso entre la ternura acontecida en uno a quien se saluda y la identidad anterior y más compleja de la comunidad así reconocida. Derrida denomina al tema en general "la cuestión del número"27.

Está fuera de cuestión en Aristóteles que el número censado de los habitantes de la ciudad no es de facto el número de los amigos. Ni los que se hallan en el registro de ciudadanos en la parroquia o el reino puede ser infinito, y como una cosa de hecho el número de ciudadanos incluye a los no amigos (y no a la inversa). Los amigos aristotélicos son un subconjunto del número finito de censados en la parroquia o el reino. El que es tratado como amigo en el saludo carece de número $\mathrm{y}$, por lo mismo, puede exceder al número del censo, y abarca ciertamente algunos no amigos aristotélicos, como el desconocido en el bosque.

Es fácil pensar que una ciudad aristotélica podría no estar compuesta solo por amigos y que, más bien, es en la Ciudad que uno tiene amigos y cuenta a Tal o cual como amigo; en la misma medida en que se dice con sentido que una ciudad (una cierta comunidad) es una es necesario que haya en ella alguna suerte de cuerpo empático. El tema que hay detrás es aquí, como ya sabemos, la cuestión del número: cómo contar, con qué criterio, cómo así es contable, a partir de qué se determina o se sabe quiénes son amigos hasta que el límite de la amistad configure un mundo, dicho ya no como la ciudad de Tal (Roma), sino como allí donde Tal puede ser contado como amigo; esto incluye la cuestión anexa de cómo un determinado número constituye el número de la Ciudad (donde Tal acontece como amigo). El mismo tema puede ser encuadrado de la siguiente manera: desde qué ámbito es posible saludar a alguien, que alguien acontezca como amigo. De la reflexión política sobre la amistad que hizo Aristóteles inferimos que es posible pensar la ciudad, es decir, el mundo de cosas que hacer, como una amistad: la amistad posible de ser contada. Esta ciudad no sería ni territorial ni jurídica, sino formada por la comunidad de los que es posible que acontezca que sean contados. La amistad aquí no es efectiva sino solo posible para aquellos de quienes el que recibe el saludo acontece como un legado; legado en la ternura que le es expresada a él, pero también junto con él a los que lo han legado, que son como él en lo en él es amado por quien lo saluda. Como debe ir 
comprendiendo el lector, el número es una dimensión aporética, pues a la vez que se cuenta al que se saluda se sabe que no se puede contar en su totalidad a todos los dignos de saludo; a la misma vez que pueden ser cien, o diez mil o trescientos veintiocho. Nunca puede descartarse uno más o bien uno menos.

Al saludar a uno se piensa una totalidad de contados que es sin embargo abierta. Respecto del asunto del número, consideramos que basta con observar la experiencia de que es posible extender el número de amigos que pueden ser pensados en la amistad acontecida en una suma superior a dos. Aristóteles consideraba que el número de los amigos no podía ser muy grande, dado que hay ciertas condiciones respecto de quién es o no amigo que nosotros no estamos tomando en cuenta, en temas que atienden a la intimidad, la comunicación o bien al grado de confianza con otro o algo parecido. Como un asunto relativo a la experiencia de saludar, todos estos rastros aristotélicos quedan suspendidos en el saludo concreto, que por ello se da más al legado que la persona acontece ser que a esta misma como Tal y Tal. Contar un número es una cuestión relativa al acontecer: acontece que tres o bien que ocho, y en cada caso el amigo que se suma y es sumado acontece por el hecho de ser sumado. Llega uno a la reunión, y es saludado. Luego llegan otros más. Hasta un intruso podría llegar después; al ser éste saludado, sería ya el intruso parte del grupo, siendo su carácter intruso un accidente en la reunión de la que, siendo intruso, sería a la vez no intruso. El mundo se amplía y se reduce en un número aporético que se sabe a la vez que se ignora. Un modo algo plástico de entender esto es revisando un antecedente bien conocido de cómo pensar la comunidad y la ciudad donde nos hallamos como amigos.

\section{LA CIUDAD DE SAN AGUSTÍN}

Sobre el tema de cuántos son los amigos podemos hacer una visita a uno de los más grandes moralistas de la latinidad cristiana, San Agustín, en su famosa obra La ciudad de Dios. El obispo de Hipona sostenía que los cristianos debían sentirse, antes que griegos o romanos, árabes o egipcios, miembros de una ciudad común; esa ciudad compartida era con certeza no territorial ni jurídica: no era Roma, por ejemplo. Sus límites se hallaban en quién podía o no ser contado, lo cual desarrolla el santo africano sobre la base de la comunidad de cosas amadas en el contado como amigo. Pero en la cuestión de contar el número, ese número en cada caso, que procede de la ternura acontecida, está siempre inexorablemente abierto a más (o a menos), sin que pueda fijarse el número nunca.

El contexto que trataba San Agustín se refería a un tipo de comunidad vinculada al modo de una amistad, que es lo que sentirse empujado a saludar a un extraño significa. En la tradición cristiana se trata de una comunidad que San Pablo en la Carta a Filemón llamó koinonía. En el Libro XIX de La ciudad de Dios se explica cómo una comunidad humana puede ser instalada en un ámbito anterior y diferente de una ciudad físicamente establecida; esto sería posible a través del amor por ciertos bienes comunes y frente a los que uno se reconoce a sí mismo (en la amistad y, por lo mismo, en el acto en que ésta acontece y alguien, un desconocido, es como amigo ${ }^{28}$. Roma o Constantinopla son asentamientos de hombres que comparten un territorio y un ordenamiento jurídico cuyo límite es ese mismo territorio donde la ley o el código tal es vigente. Siguiendo la tradición de Aristóteles, lo que califica a las ciudades como comunidades políticas no es característicamente la amistad, sino la relación del territorio, el ordenamiento jurídico, etc. Los cristianos, sin embargo, a diferencia del resto de los romanos, pertenecerían a una ciudad acontecida desde una empatía; esa ciudad constituye el título del libro de San Agustín al que se está interpretando: La ciudad de Dios; lo 
interesante es que la amistad entre los cristianos, que acontece en una ternura, muestra claramente que tiene lugar en un mundo común, no significando aquí en absoluto unas murallas perimetrales ni unos números limítrofes ${ }^{29}$. Se es (como) amigo cristiano al margen de si los miembros, en cada caso ciudadanos divinos, son de origen griego o romano, árabe o egipcio.

Espero que el lector haya ya comprendido que deseamos rescatar de San Agustín la idea de que una comunidad de personas amigas, amadas por algo común que las convoca, podrían ser un número vastamente incontable, vale decir, que careciera de límite reconocible por la inteligencia de contar. Entenderíamos que algún límite debería tener, pues no es concebible para el ser humano una amistad ilimitada con una ternura ilimitada (a toda la humanidad, por ejemplo), dado que la idea misma de amistad presupone una distinción del amigo que permite reconocerlo como aquel en cuya vista acontece la ternura. La ternura del amigo es el sentimiento que revela el reconocimiento del amigo bajo la idea de que hay algunos que no son ni serán saludados.

Invocando al docto paciencia, habría que indicar que la amistad cristiana hace a cada cristiano amigo de otro cristiano y de todos los cristianos; como referida a una ciudad, es una amistad ciudadana. Esta amistad ciudadana, vale decir, de muchos en un ámbito, tiene lugar de manera misteriosa en un mundo, que este mundo es en cada caso un mundo real (acontecido, no imaginario, meramente deseado o postulado), lo que se muestra porque puede ser descrito; no lo es por el territorio o el régimen jurídico ni, ciertamente, por el número que pueda contarse en un censo. Este ámbito constituye el mundo de cosas que hacer cristianas, esto frente a otros mundos donde lo que hacen los amigos allí sumados sean otras actividades.

La observación anterior sobre la amistad cristiana no es en absoluto banal. Un mundo de cosas que hacer no es un concepto meramente moral, ideal o argumentativo cual es el caso, por ejemplo, del mundo de cosas que hacer supuesto en los colectivos humanistas, donde caben todos los humanos, incluso sin haberlos sumado. El mundo del que se hace referencia consiste en la forma de ser adoptada por los amigos para hacer posible la amistad y, por lo mismo, es todo lo contrario de una idea moral, etc. en vista de ser hecha. Ya que se ha citado a San Agustín, se haga un viaje de regreso a la amistad cristiana.

Quienes frecuentan el cristianismo saben que en el mundo de cosas que hacer cristianas (que podrían ser budistas o de otro tipo) puede enumerarse una serie inexhausta de pautas de comportamiento que lo manifiestan y revelan y que se dibujan en objetos, que son como indicadores de las acciones que es necesario hacer para que la amistad no cese de acontecer. En ese sentido, exige desde un cierto amor así manifestado. Imaginemos a un externo situado frente al mundo de la amistad cristiana.

En un mundo común debe poder ser enumerado qué hacer, así como antes el número para saludar o ser como amigo pudo ser contado y de la misma manera relativamente a sus miembros. Como se trata de un mundo en el que es posible hacer, es un mundo que se presenta siempre con un relieve, esto es, con un conjunto altamente complejo de acciones humanas que pueden ser hechas de innumerables maneras, aunque nunca de tal manera que el número se haya agotado. No habrá dificultad, sin embargo, en reconocer qué pertenece a ese relieve de acciones cuyo conjunto es la ciudad/amistad misma. El externo de la ciudad visita el mundo que los cristianos aman. Se encuentra quien viaja de pasada por la ciudad donde se aman los cristianos como un mero turista ontológico; encuentra allí un relieve hermenéutico en el que se pasea sin comprometerse. Tiene allí delante en el relieve ceremonias y discursos, autoridades y textos de referencia, sean o no sagrados; el turista divisa en el relieve de ese mundo normas y jerarquías, hasta objetos como los trajes y las 
vasijas del sacrificio. El visitante se sorprende de que los objetos que ve llevan ellos mismos normas y jerarquías consigo, de tal modo que verlos e identificarlos en el culto es saber ya qué se hace o no se hace con ellos: una serie larga y compleja de formas de conducta y valoración cuyo número conjunto, incontable, es referido como una totalidad completa aquí a modo de un mundo. Hay allí a la vista actividades, como las plegarias, los ritos y sacrificios, por ejemplo, o bien la lectura de las fuentes de autoridad, como las cartas de San Pablo o las Actas de los mártires ${ }^{30}$.

Un mundo de cosas que hacer, una ciudad de los así unidos es el ejemplo manifiesto de que en un mundo pensado desde un saludo ha acontecido en una ternura no hay mayor verdad que esta: lo que es contiene el deber ser. De lo anterior resulta, como un corolario negativo, lo siguiente: que algo debe ser aunque no sea ni sea posible que sea en la realidad. En efecto, es altamente implausible para un mundo de cosas que hacer supuesto en un saludo creer que algo debe ser por razones distintas a lo que empuja a la amistad. Un ejemplo de esto sería que alguien haya dicho qué se debe hacer creativamente, legislado con un poder caprichoso, habiéndolo establecido a partir de un razonamiento científico o simplemente alucinado. El mundo acontecido en la comunidad cristiana a la que se refiere San Agustín es un mundo que implica exigencias ya desde siempre sabidas. Hay quienes razonan bajo la idea de que la unidad que hace política la ternura del saludo cristiano incorpora una realidad altamente creativa. Pero eso es relativamente a lo expuesto como nadar en el aire o, para acomodarnos a lo que dijera alguna vez Immanuel Kant de la filosofía religiosa, es como una paloma que, ya que se sabe capaz de volar, cree razonable demandar el derecho a volar lo más alto en el Cielo, alistando por ello las alas para agitarlas entre los cometas y las galaxias ${ }^{31}$. Si no puede volar más alto, la paloma tiene la extraña idea de que es su derecho ir más lejos. El ámbito acontecido en un saludo debe, sea lo que sea, poder ser contado de antemano como real. Es esta realidad la que hace posible que acontezca el saludo en el extraño.

\section{LA FRÁGIL FACTICIDAD}

En filosofía al conjunto del mundo de cosas que hacer/koinonía se lo llama de muchas maneras; siendo como una ciudad, llamaremos aquí a esto "facticidad": que el mundo sea posible, que algo debe ser aunque no sea realmente ni sea posible que sea, y esto porque en orden a la comprensión es al mismo tiempo algo que es hecho ${ }^{32}$. El mundo amado que acontece en el saludo no es definitivo, como no lo es siquiera el mero saludo al desconocido, que bien puede o no puede acontecer.

Con "facticidad" queremos significar aquí el acontecer del mundo, como en el saludo, como un todo que se relaciona con y llama personas: con amigos presentes y pasados, y posibles futuros amigos. Llamaremos a esto un todo apelativo, en que el mundo es llamado y se experimenta como aconteciendo o naciendo incesantemente como una realidad. Martin Heidegger empleó "facticidad" en 1923 para referirse a algo semejante para significar que a la vez este mismo mundo es allí donde es lo que es, razón por la cual hizo equivalente la idea de facticidad, un mundo donde acontecen acciones humanas, con la de ontología, es decir, un mundo donde es el ser lo que acontece ${ }^{33}$. Ha hecho notar Hans-Georg Gadamer el carácter eminentemente práctico de esta manera de enfocar el ser como facticidad ${ }^{34}$.

Una característica de lo fáctico es que es siempre una experiencia temporal, que acaece como tiempo de la experiencia en que lo fáctico tiene su lugar. Un mundo fáctico, como el mundo de cosas que hacer creemos que exige al saludar, puede definirse como el incesante aparecer en una 
continuidad inacabada, de la cual cada parte se integra en un cierto tiempo. En la facticidad acontece como amigo lo presente, aunque como ya se habrá notado, acontece también lo pasado como algo que se hace presente en el saludo. Por ello la exigencia del (amigo) presente, lo que en cada caso se exige como cosa qué hacer en un mundo de amigos agentes operadores, es también la exigencia del pasado en cuya amistad el presente del mundo también acontece.

Es una antigua norma de sabiduría popular el deber de cuidar a los amigos; esto se debe al riesgo de poder perderlos. En este mundo hecho en cada caso hay un cierto grado de seguridad, que procede de la exigencia misma de lo que debe ser hecho, más un margen en cada caso indeterminado de lo que en efecto acontece. En este margen el mundo de amigos se arriesga en el acontecer, por ejemplo, de que algo salga mal. Uno saluda, por así decirlo, a la persona equivocada. Este riesgo es lo que el mundo de cosas que hacer tiene de expectante. Se remite al lector a un texto de Heidegger que es un comentario sobre la ontología de la voluntad de poder de F. Nietzsche, pero que es en gran medida a la vez un comentario de la metafísica de G. Leibniz sobre el deseo de ser que encierra una naturaleza que, ya siendo, podría no ser. Heidegger relaciona a Nietzsche con Leibniz a través del término appetitus, esto es, dicho en nuestras palabras, el deber de ser hecha de una esencia, interpretada en Heidegger (y aquí también) como un mundo de hombres que pide ser hecho; éste se arriesga así en su pedir a la frágil facticidad (del amigo que hace) para conservarse y seguir siendo ${ }^{35}$.

Una vez hecha la consideración de que el mundo de cosas que hacer es una dimensión fáctica, debe recordarse lo que antes se dijo relativamente a que el mundo de cosas que hacer es aquello que da lugar a lo que debe ser hecho; consiste en su impulso (su appetitus), por decirlo de alguna manera. Se halla en el impulso de saludar, ciertamente, al amigo que en cada caso uno es empujado a saludar. El mundo de cosas que hacer es operado por agentes humanos que actúan como amigos, en un acontecer constante de personas que realizan acciones bajo el reconocimiento que hace posible la ternura de la amistad. En este contexto lo que hay determina lo que debe ser, entendiendo esto de manera tal que el sentido mismo de hacer es continuar (que el mundo de cosas que hacer y exige ser siga siendo), incluso si eso acarrea ciertos riesgos. No hay, sin duda, continuidad sin riesgo, aunque tampoco un mundo humano se halla exigido de arriesgarse, sino que se halla con que se arriesga.

El relieve constituido por un mundo de cosas que hacer, como ya hemos tratado de explicar, aunque desea, tiene el apetito de seguir, puede sufrir así mutaciones; esto, aunque imperceptible, lo atestiguamos al ver estas cosas del mundo de cosas que hacer ya hecho a lo largo del tiempo. Un conjunto de descuidos, actos de mala voluntad, algo de idiotez, etc., hacen que en el relieve del mundo se mezclen elementos que, a la vez que están, sabemos que no son de allí, que son elementos que no pertenecen y que si predominaran en algún momento sobre los que sabemos debe ser, habrían gestado otro mundo, para decirlo de alguna manera. Eso, sin embargo, este conjunto de cosas que hacer abandonadas, incumplidas, mal realizadas, etc., no puede acontecer de modo tal que le sea imposible al amigo del que en cada caso es amigo no reconocer en lugar de su amistad: en el lugar de la ternura, tendrá también alojada una especie de tristeza, que es la huella de lo que se halla ausente en el relieve.

Imaginemos ahora los lectores y yo mismo desprovista la amistad cristiana tal y como San Agustín trató de hacerla diferente de una comunidad política territorial y jurídica. Supongamos que se hayan ausentes las cosas que hacer que hacen cristiana en cada caso la experiencia cristiana de saludar a un cristiano; pensar esto y a la vez remitir los amigos a la amistad cristiana implica un imposible práctico; esto es así incluso cuando la experiencia media en general de un mundo cualquiera de cosas que hacer, lo normal, por así decirlo, hubiese como desaparecido. En caso de que 
sea más lo que falte que lo que haya, es superficial y poco reflexivo pensar que eso que es ausente es deseable en la calidad misma de que ya no está y es ahora causa de tristeza. En tiempo reciente Gianni Vattimo quiso expresar de manera afirmativa lo anterior, la ausencia de lo que da tristeza como algo deseable, cosa que hizo para diagnosticar el supuesto carácter deseable del nihilismo de las sociedades democráticas capitalistas liberales avanzadas; sostuvo que era un gran bien que tantas cosas exigidas del cristianismo fueran ausentes ${ }^{36}$.

El generalizado incumplimiento de lo que se describe como que es, lo que sabemos que es; allí aparece la exigencia: el no ser de lo que es exige que sea lo que falta, se pide lo que falta como parte del acontecimiento de que falta. Todo lo que no sucede constituye en un relieve de asuntos por hacer ausentes, increíblemente, un extensivo horizonte de mundo de cosas que hacer que a la vez son cosas que quedan por hacer, es decir, cosas cuyo hacer se halla en suspenso; se trata de cosas que se hallan en trámite, por así decirlo. Hay una larga referencia a este tema de las acciones que deben ser hechas y quedan suspendidas que se ha hecho en torno al cuento de Herman Melville Bartleby, el escribiente: se cuenta allí la historia de un trabajador en este trámite permanente de postergar o mantener en suspenso su trabajo, en lo que Giorgio Agamben ha explotado la idea de la capacidad o potencia de que no, la capacidad de suspender encerrada en toda potencia de actuar ${ }^{37}$.

\section{CONCLUSIONES}

Dar la mano, saludar, es un gesto ordinario y común, en el que sin embargo hemos mostrado se hace manifiesta una dimensión anterior, que hemos aquí intentado relacionar con el tema más general relativo al pensamiento de la amistad, así como al vínculo entre la empatía que empuja al saludo y las posibles consecuencias de esta empatía en un sentido político.

Lejos de ser un simple acto de gentileza social, dar la mano o saludar es postulado aquí como huella ontológica de un agrupamiento, del cual da muestra como signo y acontecimiento de un mundo de exigencias con el que ya desde siempre se está comprometido. Para esto hemos partido de las sugerencias en ese sentido esbozadas escuetamente por G. Agamben al comentar el libro IX de la Ética a Nicómaco de Aristóteles, en particular a las referencias de este libro relativas a configurar un mundo común, una cierta comunidad. Siguiendo la línea reflexiva de J. Derrida en Políticas de la amistad, hemos reconocido y subrayado las manifiestas diferencias en Aristóteles entre la comunidad política y la comunidad de amigos. Se ha adoptado sin embargo un enfoque alternativo al desarrollado por Derrida. Desde un ángulo más bien fenomenológico, se ha enfocado el tipo de sentimientos relativos a la amistad a partir del saludo. En el saludo se encuentra un tipo peculiar de empatía, de tal modo que las acciones de saludar, como dar la mano, no se dirigen al amigo, sino al que en cada caso es reconocido como amigo. Esto marca una diferencia, pues el como amigo no es sin duda necesariamente amigo, y puede incluso ser un completo desconocido. El como amigo del saludo súbito tiene la ventaja frente al enfoque de quien es amigo, como en Aristóteles, Agamben o Derrida, que permite extraer una serie de consecuencias interesantes desde el punto de vista conceptual para vincular la amistad y la política. Mientras que es sin duda problemático pensar una ciudad conformada por amigos con los que se practica la virtud a la que el capítulo IX de la Ética a Nicómaco se refiere, no es problemático el vínculo del trato de darle a alguien la mano como amigo y lo que ese gesto pone de manifiesto, algo que se ha ejemplificado a partir de La ciudad de Dios de San Agustín. 
El saludo conlleva una descripción de qué se exige del saludado, y de los que son así contables como amigos, cuyo número es una suma incontable que se da al modo de acontecimientos, donde el saludo mismo incluye, así como su omisión excluye; la amistad acontecida en la ternura de ese contar que es saludar es así como una exigencia relativa a algo que es un todo de todos, lo que es amable y deseable en el saludo ${ }^{38}$. Comprender en general, pero esta vez comprenderse como en compromiso de amor con un mundo, conocer ese mundo y lo que es, implica también el deber de hacerlo ser, de procurar que acontezca o, sería mejor decir, que continúe aconteciendo, puesto que exige ser. El mero saludar a alguien como amigo es un acontecimiento del mundo implicado en el gesto.

\section{Bibliografía}

Agamben, G., ¿Qué es un dispositivo? Seguido de El amigo y de La Iglesia y el Reino, Barcelona, Anagrama, 2015 [2006].

Agamben, G., ¿Qué es filosofía?, Buenos Aires, Adriana Hidalgo editora, 2017 [2016].

Araiza, J., “Sobre la amistad según la teoría ética de Aristóteles”, Nova tellus, 23/2 (2005), pp. 125-159.

Anscombe, E., “Modern Moral Philosophy”, Philosophy, 33/124 (1958), pp. 1-19.

Aristóteles, Ética a Nicómaco, Madrid, Gredos, 2005.

Baumer, F., El pensamiento europeo moderno. Continuidad y cambio en las ideas, 1600-1950, México, Fondo de Cultura Económica, 1985 [1977].

Biset, E., "Derrida y lo político”, Confines, 30 (2013), pp. 23-37

Campos, V., Violencia y fenomenología. Derrida, entre Husserl y Levinas, Santiago de Chile, Metales pesados, 2017.

Conill Sancho, J., Ética hermenéutica. Crítica desde la facticidad, Madrid, Tecnos, 2006.

Deleuze, G., Agamben, G. y L. Pardo, Preferiría no hacerlo. Bartleby, el escribiente de Herman Melville más tres ensayos sobre Bartleby, Valencia, Pretextos, 2005.

Derrida, J. Políticas de la amistad. Seguido de El oído de Heidegger, Madrid, Trotta, 1998 [1994].

Descartes, R., Las pasiones del alma, Madrid, Tecnos, 1996.

Dri, R., "Filosofía política aristotélica", A. Boron (comp.), La filosofía política clásica. De la Antigüedad al Renacimiento, Buenos Aires, Clacso, 2000, pp. 97-130.

Durantaye, L. de la, Giorgio Agamben. A Critical Introduction. Stanford, Stanford University Press, 2009.

Eusebio de Cesarea, Historia eclesiástica, Madrid, Biblioteca de autores cristianos, 2010.

Gadamer, H-G., “Autopresentación”, Verdad y Método II, Salamanca, Sígueme, 1992 [1977], pp. 373-402.

Gadamer, H-G., "La filosofía griega y el pensamiento moderno”, Antología. (2001 [1978]), Salamanca, Sígueme, pp. 259-266.

Gadamer, H-G., Los caminos de Heidegger. Traducción de Angela Ackermann Pilarì, Barcelona, Herder, 2003 [2002].

Garcés, L. y C. Giraldo, "Las emociones y las pasiones en Aristóteles; conceptualización e interpretación", Revista Espacios, 39/4 (2018), pp. 26-36.

Garcés, L., Huerta, O. y A. Arboleda, "El amigo en Aristóteles como posibilidad de autoconocimiento y las diferencias con un adulador", Revista lasallista de investigación, 14/2 (2017), pp. 192-202.

Giusti, M., "Economía, sociedad y política. Una moderna confusión conceptual, VV AA, Búsquedas de la filosofía en el Perú de hoy, Cuzco, Bartolomé de las Casas, 1992, pp. 57-83. 
Giusti, M., Tras el consenso. Entre la utopía y la nostalgia, Madrid, Dyckinson, 2006.

Grondin, J., ¿Qué es la hermenéutica? Barcelona, Herder, 2008 [2006].

Heidegger, M., "La frase de Nietzsche "Dios ha muerto", Sendas perdidas .Holzwege], Buenos Aires, Losada, 1960 [1943], pp. 174-221

Heidegger, M., El Ser y el Tiempo [Sein und Zeit], México, Fondo de Cultura Económica, 1983 [1927].

Hernández de la fuente, D., “La noción de koinonía y los orígenes del pensamiento utópico”, Studia Philologica Valentina, 16/13 (2014), pp.165-196.

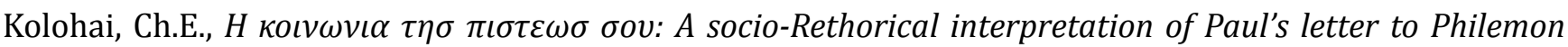
(Tesis de doctorado), Suva, Pacific Theological College Suva, 2013.

Lacunza, M., "La amistad como núcleo de la vida política actualidad del pensamiento de Aristóteles", Nuevo Itinerario, 11 (2016), pp. 81-92.

López, A., "Reseña de Políticas de la amistad seguido de El oído de Heidegger" de Jacques Derrida", Signos Filosóficos, 1/1 (1999), pp. 241-243.

Llevadot, L., “Consideraciones en torno a lo político en el pensamiento de Derrida”, Enhorabuena, 48 (2012), pp. 95-109.

Llevadot, L., "No hay mundo común: Jacques Derrida y la idea de comunidad", Isegoría: Revista de filosofía moral y política, 49 (2013), pp. 549-566.

Luc, P., La sociedad propuesta por San Agustín en su libro De Civitate Dei, Bogotá, Pontificia Universidad Javeriana. Tesis de grado.

Mills, Ch., The Philosophy of Agamben. Montréal/Kingston, McGill-Queen's University Press, 2008.

Moreau, J., Aristóteles y su escuela, Buenos Aires, Eudeba, 1979.

Polo, L., “La amistad en Aristóteles”, Anuario filosófico, 32 (1999), pp. 477-485.

Powell, J., Jacques Derrida. Una biografía, Valencia, Universidad de Valencia, 2008.

Redaelli, W., "Evento”, en R. Ronchi (Ed.), Filosofia teoretica. Un'introduzione, Torino, UTET, pp. 21-45.

Rivera, VS., "Charlie Hebdo. El evento del fin del nihilismo cumplido”, Estudios Filosóficos, 64/187 (2015), pp. 531-554.

Rivera, VS., "Evento y milagro. El 11 de septiembre: ¿Gianni Vattimo o Joseph de Maistre?”, Diánoia, 62/79 (2017), pp. 40-75.

Ruiz Bueno, Daniel, Actas de los mártires, Madrid, Biblioteca de autores cristianos, 2018.

Vattimo, G., Introducción a Heidegger, Barcelona, Gedisa, 2006 [1971].

Vattimo, G., De la realidad. Fines de la filosofía, Barcelona, Herder, 2013 [2012].

Volpi, F., Aristóteles y Heidegger, México, Fondo de Cultura Económica, 2012.

Notas

1 Cf. G. Agamben, ¿Qué es un dispositivo? Seguido de El amigo y de La Iglesia y el Reino, Barcelona, Anagrama, 2015 [2006]. Cf. Sobre Agamben y Aristóteles en este punto, M. Lacunza, "La amistad como núcleo de la vida política. Actualidad del pensamiento de Aristóteles", Nuevo Itinerario, 79 (2016), pp. 81-92.

2 J. Derrida, Políticas de la amistad. Seguido de El oído de Heidegger, Madrid, Trotta, 1998 [1994]. Especialmente pp. 56 y ss. Cf. la reseña de Adrián López, "Reseña de Políticas de la amistad seguido de El oído de Heidegger de Jacques Derrida", Signos Filosóficos, 1/1 (1999), pp. 241-243.

3 L. Llevadot, "Consideraciones en torno a lo político en el pensamiento de Derrida”, Enhorabuena, 48 (2012), pp. 95-109; L. Llevadot, “No hay mundo común: Jacques Derrida y la idea de comunidad”, Isegoría: Revista de filosofía moral y política, 49 (2013), pp. 549-566. 

fenomenología. Derrida, entre Husserl y Lévinas, Santiago de Chile, Metales pesados, 2017. Eudeba, 1979, pp. 222 y ss.

6 Cf. L. Polo, "La amistad en Aristóteles", Anuario filosófico, 32 (1999), pp. 477-485; J. Araiza, "Sobre la amistad según la teoría ética de Aristóteles", Nova tellus, 23/2 (2005), pp. 125-159.

$7 \quad$ Aristóteles, Ética a Nicómaco, Madrid, Gredos, p. 277, ET 1169b.

8 Si la expresión "exigencia" u otras derivadas fuese problemática, habría que remitir preferentemente al tratamiento dado por G. Agamben de este término en la tradición metafísica; cf. G. Agamben, ¿Qué es filosofía? Buenos Aires, Adriana Hidalgo Editores, 2017, pp. 49 y ss.

9 L. Garcés, O. Huerta y A. Arboleda, "El amigo en Aristóteles como posibilidad de autoconocimiento y las diferencias con un adulador”, Revista lasallista de investigación, 14/2 (2017), pp. 192-202.

10 Sobre el empleo contemporáneo de evento en la literatura filosófica $c f$. W. Redaelli, “Evento", R. Ronchi (ed.), Filosofia teoretica. Un'introduzione, Torino, UTET, 2009, pp. 21-45.

11 En este texto evento (y acontecimiento, así como los derivados de ambos) integra el carácter del tono emotivo de lo que en efecto ha sucedido y llama la atención, así como la peculiar incapacidad de comprenderlo. Seguimos VS. Rivera, "Evento y milagro. El 11 de septiembre: ¿Gianni Vattimo o Joseph de Maistre?”, Diánoia, LXII/79 (2017), pp. 40-75; VS. Rivera, "Charlie Hebdo. El evento del fin del nihilismo cumplido", Estudios Filosóficos, 54/187 (2015), pp. 531-554.

12 En esto debo gratitud a la conferencia El amigo, de Giorgio Agamben, incluida en G. Agamben, ¿Qué es un dispositivo? Seguido de El amigo y de La Iglesia y el Reino, Barcelona, Anagrama, 2015 [2006], pp. 137 y ss.

13 Usaremos en delante de referencia a esta obra la edición de José Gaos, El Ser y el Tiempo (abreviada en adelante SZ por sus iniciales en alemán): Heidegger 1983 [1927]; cf. SZ numerales 29 y ss., Martin Heidegger, El Ser y el Tiempo[Sein und Zeit]. Traducción de José Gaos, México, Fondo de Cultura Económica, 1983 [1927], pp. 151 y ss. Como introducción al rol de los sentimientos en la hermenéutica de Heidegger, $c f$. G. Vattimo, Introducción a Heidegger, Barcelona, Gedisa, 2006 [1971], pp. 36 y ss.

$14 C f$. L. Garcés y C. Giraldo, "Las emociones y las pasiones en Aristóteles; conceptualización e interpretación", Revista Espacios, vol. 39, núm. 4 (2018), pp. 35-36.

15 Si el docto piensa que se usa aquí sin más el concepto heideggeriano de estar en un mundo, debemos aclararle cierta diferencia de énfasis de nuestra parte. Para SZ, el mundo es ante todo una experiencia en la que se halla una constelación de posibilidades de hacer o no hacer. Pero justamente porque se trataba de posibilidades de hacer o no hacer, Heidegger pensaba que estas no generaban obligaciones o exigencias. Esto se debe a que, por las razones que sea, pensaba en el mundo como una apertura para hacer, antes que como un compromiso. La experiencia media del mundo, en este sentido, no era aún una exigencia, que es lo mismo que decir que carecía de una esencia o de que no había en el mundo o cabía encontrar esencias, lo que tiene como consecuencia creer que la experiencia media del mundo carece de contenido normativo. Es evidente que aquí se sostiene, en sentido general, lo contrario. Cf. G. Vattimo, Introducción a Heidegger, op. cit., pp. 44 y ss.

16 Cf. P. Pavesi, La moral metafísica. Pasión y virtud en Descartes, Buenos Aires, Prometeo libros, 2008, pp. 51 y ss. Respecto del texto original del francés, R. Descartes, Las pasiones del alma. Estudio preliminar y notas de José Antonio Martínez, Madrid, Tecnos.

17 Escribe Hans-Georg Gadamer a propósito del amor en El Banquete de Platón: "La amistad es en la reflexión filosófica un título de la solidaridad. Pero la solidaridad es una forma de la experiencia del mundo y de la realidad social, una forma que uno no puede hacer, que no puede planear por medio del dominio objetivante ni es capaz de introducir mediante instituciones artificiales", H-G., "La filosofía griega y el pensamiento moderno", Antología, Salamanca, Sígueme, 2001 [1988], p. 263.

18 Cf. en general el lector curioso para la atmósfera de la cultura cientificista que aquí se alude A. Baumer, El pensamiento europeo moderno. Continuidad y cambio en las ideas, 1600 - 1950), México, Fondo de Cultura Económica, 1985 [1977], especialmente pp. 286 y ss.

19 Se usa aquí "dispositivo” en la forma como ha sido acuñado por G. Agamben, “¿Qué es un dispositivo?”, ¿Qué es un dispositivo?, op. cit. pp. 35 y ss.

20 No siendo este texto una exégesis de Aristóteles, se remite a Ética a Nicómaco, op. cit. p. 277- 278, ET 1169b; esto mismo es desarrollado en ibid., pp. 280 y ss., ET $1170 b$. 
Como una introducción a este tema $c f$. M. Giusti, "Economía, sociedad y política. Una moderna confusión conceptual”, VV AA, Búsquedas de la filosofía en el Perú de hoy, Cuzco, Bartolomé de las Casas, 1992, pp. 57-83. Como referencia $c f$. M. Giusti, Tras el consenso. Entre la utopía y la nostalgia, Madrid, Dickynson, 2006, pp. 85 y ss.; R. Dri, "Filosofía política aristotélica”, en A. Boron (comp.), La filosofía política clásica. De la Antigüedad al Renacimiento, Buenos Aires, Clacso, 2000, p. 115.

Cf. J. Powell, Jacques Derrida. Una biografía, Valencia, Universidad de Valencia, 2008, pp. 225 y ss.

Vid. Aristóteles, Ética a Nicómaco, op. cit., p. 278, ET 1171a.

Derrida establece esta reflexión: “Esta cuenta” relativa a "(Un número) ¿Dónde empieza y acaba? ¿En uno más uno? ¿En una? ¿En cada uno, en cada una? ¿Quiere usted decir en todos y en todas, en cada quién?”. Se señala aquí la paradoja de a partir de qué el número de cada quién es o llega a ser el número de la Ciudad; se trata de un asunto por lo demás interesante, pues atiende al límite de quiénes son "la Ciudad": Las fronteras y, por ello mismo, la identidad de la Ciudad. Se trata del límite político de la amistad. Es lamentable que Derrida no fuera muy claro en responder a sus propias inquietudes, que dejan tras sus reflexiones una pátina de algo a la vez místico e imposible. Texto ligeramente adaptado, $c f$. J. Derrida, Políticas de la amistad. Seguido de El oído de Heidegger, Madrid, Trotta, 1998 [1994], pp. 14-15.

27 Cf. J. Derrida, Políticas de la amistad, op. cit., p. 206.

28 Cf. P. Luc, La sociedad propuesta por San Agustín en su libro De Civitate Dei, ¿es algo puramente escatológico o algo en parte realizable? Bogotá, Pontificia Universidad Javeriana. Tesis de grado, p. 8.

29 Para el caso de San Agustín debe añadirse la noción de "comunidad" propia de la Iglesia en su etapa antigua, cuyo rastreo nos lleva a la carta de San Pablo a Filemón, y donde "ciudad" usado por San Agustín remite antes que a polis (ciudad Estado griega) al griego koinonía. Cf. D. Hernández de la fuente, "La noción de koinonía y los orígenes del pensamiento utópico”, Studia Philologica Valentina, 16/13 (2014), pp.165-196; Charles Edward

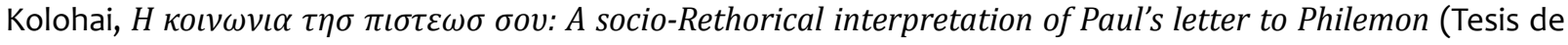
doctorado), Suva, Pacific Theological College Suva, 2013.

30 La versión más reciente en español es la que fuera editada por D. Ruiz Bueno, Actas de los mártires, Madrid, Biblioteca de autores cristianos, 2018. Para la historia de la iglesia cristiana en la época de San Agustín, Eusebio, Historia eclesiástica, Madrid, Biblioteca de autores cristianos, 2010.

31 Cf. I. Kant, Crítica de la razón pura. Prólogo, traducción, notas e índices de Pedro Ribas, México, Taurus, 2008 [1781], pp, 46-47.

32 Quizá le sea útil al lector amigo no docto a la vez esta cita incidental y no académica de Hans-Georg Gadamer sobre este asunto: "La ayuda conceptual para la problemática del comprender la ofreció la elaboración por Heidegger de la estructura existencial de la comprensión, que él llamó primero hermenéutica de la facticidad, la autointerpretación de lo fáctico, es decir, de la existencia humana real”, H-G. Gadamer, "Autopresentación", Verdad y Método II, Salamanca, Sígueme, 1992 [1977], p. 390, ligeramente adaptado; subrayado el original con comillas. En general vid. J. Grondin, ¿Qué es la hermenéutica? Traducción de Antoni Martínez Riu, Barcelona, Herder, 2008 [2006], pp. 45 y ss.; J. Conill Sancho, Ética hermenéutica. Crítica desde la facticidad, Madrid, Tecnos, 2006, pp. 91 y ss.

33 Cf. en español como M. Heidegger, Ontología. Hermenéutica de la facticidad, Madrid, Alianza, 1999.

34 Cf. H-G. Gadamer, Los caminos de Heidegger, Barcelona, Herder, 2003 [2002], pp. 329-332. Sobre Heidegger y la filosofía práctica de Aristóteles vid. F, Volpi, Aristóteles y Heidegger, México, Fondo de Cultura Económica, 2012.

$35 C f$. M. Heidegger, "La frase de Nietzsche "Dios ha muerto", Sendas perdidas [Holzwege], Buenos Aires, Losada, 1960 [1943], pp. 174-221.

36 Cf. G. Vattimo, De la realidad. Fines de la filosofía, Barcelona, Herder, 2013 [2012], caps. 6, 7.

37 Vid. G. Deleuze, G. Agamben y L. Pardo, Preferiría no hacerlo. Bartleby, el escribiente de Herman Melville más tres ensayos sobre Bartleby, Valencia, Pretextos, 2005. Como introducción al pensamiento de Agamben vid. L. de la Durantaye, Giorgio Agamben. A Critical Introduction, Stanford, Stanford University Press, 2009; C. Mills, The Philosophy of Agamben, Montréal/Kingston, McGill-Queen's University Press, 2008.

38 Cf. E. Anscombe, "Modern Moral Philosophy", Philosophy, 33/124 (1958), pp. 1-19. 